\title{
Detection of Hyaluronidase and Streptokinase Virulence Factors from Streptococcus pyogenes
}

\author{
Yasameen T. Ahmed ${ }^{1}$, Nedhaal S. Zbar and Abdulwahid B. Al-Shaibani \\ Department of Biotechnology, College of Science, Al-Nahrain University. \\ ${ }^{1}$ E-mail: yasamin.thaer@gmail.com.
}

\begin{abstract}
This study was designed to detect and evaluate two of the virulence factors, hyaluronidase and streptokinase, produced by local isolates of Streptococcus pyogenes obtained from children suffering from pharyngitis. Results showed that 30 out of 135 suspected bacterial isolates obtained from 85 pharyngeal swapswere able to produce hemolysis and considered to belong to Group A streptococci. Only 4 of these were sensitive to bacitracin, and were regarded as $S$. pyogenes. All four isolates were able to produce streptokinase by using the casinolytic assay method, only 3 of them showed ability to produce hyaluronidase by using two methods; plate assay method and turbidity reduction assay method.
\end{abstract}

Keywords: Streptococcus pyogenes, hyaluronidase, streptokinase, pharyngitis.

\section{Introduction}

Group A streptococci (GAS), as Streptococcus pyogenes, is an important group of Gram-positive extracellular bacterial pathogens. It species colonize the throat or skin and responsible for a number of suppurative infections and nonsuppurativesequels. As pathogens they have developed complex virulence mechanisms to avoid host defenses (1).

They are the most common cause of bacterial pharyngitis and are the cause of scarlet fever and impetigo. The concept of distinct throat and skin strains arose from decades of epidemiological studies, in which it became evident that there are serotypes of group A streptococci with a strong tendency to cause throat infection, and similarly; there are other serotypes often associated with impetigo (2).

GAS produce and release into the surrounding medium a large number of biologically active extracellular products (4). Streptokinases are a family of secreted streptococcal proteins with the common function of converting plasminogen to plasmin. Human plasminogen is often used by invasive bacteria as a virulence factor and this process has been recognized as a critical step in S. pyogenes invasion (3).

Coleet al. (2006) mentioned that same mechanisms are exploited by $S$. pyogenes to promote systemic spread. Plasminogen bound to the bacterial cell surface may also be converted into plasmin through the action by the activity of the GAS plasminogen activatorstreptokinase (SK) (5). SK is a highly efficient plasminogen activator that plays a critical role in the invasive pathogenesis of GAS (6).

Production of hyaluronidase by group A streptococci had been suggested to aid the organism in its spread through the connective tissue hence, hyaluronidase had been designated as one of the spreading factors of microbial origin, because of its ability to attack the hyaluronic acid present in the cement substance of host tissues (7).

Upon such importance of hyaluronidase and streptokinase as virulent factors in the pathogenicity of $S$. pyogenes, this study was aimed to use various assays to detect and evaluate production of these two enzymes from bacterial isolates obtained from children suffering of pharyngitis.

\section{Materials and Methods \\ -Microbial isolates}

A total of 85 throat swabs were collected from children infected with pharyngitis. The samples were streaked on sheep blood agar medium (Himedia, India) and incubatedat $37^{\circ} \mathrm{C}$ for $24 \mathrm{~h}(8)$. After incubation, isolates which gave clear zones of hemolysis around their colonies were purified through repeated streaking on fresh agar plates of medium. Then 
bacterial isolates were maintained on slant of brain heart infusion agar medium (Himedia, India).

\section{-Bacterial identification}

The selected isolates were identified based on their morphological and biochemical characteristics. The morphological characterizeation involves shape and Gram reaction.

Biochemical characterization for the isolates was includes indole, methyl red, Voges-Proskauer, citrate utilization and bile esculin agar tests, in addition to growing the isolates presence of $6.5 \% \mathrm{NaCl}, 40 \%$ bile and growth under anaerobic conditions. The isolates were, then, tested for its ability to ferment lactose, sucrose, maltose and glucose according to the Bergey's Manual of Systematic Bacteriology (9).

\section{-Hyaluronidase assay}

Turbidity reduction assay method (10)

To $1 \mathrm{ml}$ of substrate [containing $0.25 \mathrm{ml}$ hyaluronic acid, $0.5 \mathrm{ml} \mathrm{D.W}$. and $0.25 \mathrm{ml}$ of acidified bovine serum albumin (BSA) fraction $\mathrm{V}(1 \% \mathrm{w} / \mathrm{v})$ in $0.5 \mathrm{M}$ sodium acetate buffer ( $\mathrm{pH} 3.1)] 0.5 \mathrm{ml}$ of the supernatant of an 18-24 $\mathrm{h}$ broth each culture of bacterial isolates was added, mixed and incubated at 37 ${ }^{\circ} \mathrm{C}$ for $30 \mathrm{~min}$. At the end of incubation period, the tubes were cooled in an ice bath. To the top of the mixture, $0.1 \mathrm{ml}$ of acetic acid $(2 \mathrm{~N})$ was added to precipitate the remaining hyaluronic acid. Tubes containing sterile broth or broth from inactive cultures should become turbid while those containing broth from hyaluronidase producing organism remain clear upon addition of the acid. Determination of hydrolyzed zone of hyaluronidase (11):

The culture of each isolate grown on slant was transferred into conical flask containing $25 \mathrm{ml}$ sterile brain heart broth before incubation at $37^{\circ} \mathrm{C}$ for $24 \mathrm{hrs}$. A portion of 5 $\mathrm{ml}$ broth was then drawn, centrifuged at $4{ }^{\circ} \mathrm{C}$ (8000 rpm for $20 \mathrm{~min}$ ) and clear supernatant was collected. Then, $25 \mu \mathrm{l}$ of the clear supernatant of each selected isolate were aseptically added into sterile wells of 20 different molten brain heart agar plates containing $1 \mathrm{ml}$ of substrate hyaluronic acid at a concentration of $10 \mathrm{mg} / \mathrm{ml}$. The plates were then incubated at $37^{\circ} \mathrm{C}$ for $24 \mathrm{hrs}$. Diameters of the hydrolyzed zones of isolates were recorded in $\mathrm{mm}$ (11).

\section{-Streptokinase assay}

Upon overnight incubation, the individual cultures were, separately, centrifuged at $10,000 \mathrm{~g}$ for $30 \mathrm{~min}$. The cell free supernatants were filtered through $0.45 \mu \mathrm{m}$ cellulose acetate filter and the filtrates were considered as crude streptokinase enzyme (12). The cell free supernatants were loaded on to the commercially available skimmed milk agar plates (Himedia, India) and incubated at $37^{\circ} \mathrm{C}$ for $12 \mathrm{hrs}$. Following incubation, diameters of the caseinolysis zones were measured to the nearest millimeter. Actual count of hydrolytic ability of respective isolate was determined by subtracting the diameter of the well from the zone of caseinolysis (13).

\section{Results and Discussion \\ Identification of isolates:}

After subjecting the 135 suspected bacterial isolates to the related biochemical tests, results showed that 30 of them were able to form hemolysis zones, and only 4 of these were sensitive to bacitracin. The four bacitracin sensitive isolates were selected and identified for subjection to the remaining biochemical tests. Result tabulated in Table (1) showed that all the four isolates were negative to catalase, oxidase, and gelatinase tests, as well as to the methyl red, Simon citrate, Voges-Proskauer and Indole tests. The suspected isolates showed also no ability to hydrolyze esculin neither tolerating bile salt. Regarding fermentation, they were able to ferment lactose, maltose, mannitol and glucose, but unable to ferment ribose and sorbitol. Such characteristics are similar to those of Streptococcus pyogenes as described by Berge's Manual of Determinative Bacteriology (9). 
Table (1)

Biochemical characterization of children pharyngitis isolates of Streptococcus pyogenes.

\begin{tabular}{|c|c|c|c|c|}
\hline \multirow{2}{*}{ Biochemical test } & \multicolumn{4}{|c|}{ Isolate symbol } \\
\hline & S16 & $S 20$ & $S 28$ & S30 \\
\hline $\begin{array}{l}\text { Growth under anaerobic } \\
\text { condition }\end{array}$ & + & + & + & + \\
\hline$\beta$-hemolysis & + & + & + & + \\
\hline Catalase & - & - & - & - \\
\hline Oxidase & - & - & - & - \\
\hline Indole & - & $\overline{-}$ & 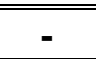 & 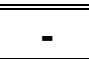 \\
\hline Methyl red & - & - & - & - \\
\hline Voges-Proskauer & 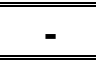 & 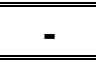 & 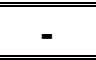 & 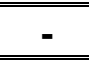 \\
\hline Simon Citrate & - & $\overline{-}$ & - & - \\
\hline Growth in $6.5 \% \mathrm{NaCl}$ (bile salt) & 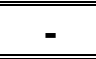 & 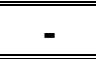 & 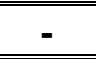 & 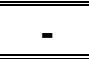 \\
\hline Hydrolysis of esculin & - & - & - & - \\
\hline Gelatin hydrolysis & - & $\overline{-1}$ & 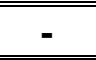 & 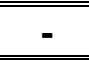 \\
\hline \multicolumn{5}{|c|}{ fermentation and acid production from } \\
\hline Lactose & + & + & + & + \\
\hline Maltose & + & + & + & + \\
\hline Glucose & + & + & + & + \\
\hline Mannitol & + & + & + & + \\
\hline Sorbitol & - & - & - & - \\
\hline Ribose & - & - & - & 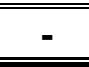 \\
\hline
\end{tabular}

(+) positive, (-) negative.

\section{Hyaluronidase production}

Results showed that, three bacterial isolates of $S$. pyogenes symbol (S16, S20, S28) were able to produce hyaluronidase enzyme by using both plate method and turbidity reduction assay in the determination of hyaluronidase. Using the plate method, addition of acetic acid on surface of platesled to the appearance of hydrolysed zonesaround of the wells which were previously filled with the supernatant of overnight $S$. pyogenes cultures; which indicates apositive result. (16) While wells of the non-producing isolates appeared not surrounded by the hydrolysed zones.

Table (2) shows that highest hydrolysed zone was recorded by isolate S16 of $S$. pyogenes when the diameter reached $12 \mathrm{~mm}$. Upon such result, this isolate was selected to be used for qualitative determination of the enzyme. The principle of using turbidity reduction assay for detection of hyaluronidase was depended on reduction turbidity of the medium when inoculated with hyaluronidase producing $S$. pyogenes isolates. After $30 \mathrm{~min}$ of incubation, the medium was isolates exhibiting reduction in turbidity as given in Table (2).

appeared as a clear broth (positive result), while that of the non-hyaluronidase producing isolates remained turbid (negative result).

Tubes containing sterile broth or broth from inactive cultures became turbid while those from hyaluronidase producing organism remained clear on addition of the acid.

Table (2)

Screening of S. pyogenes isolates for production of hyaluronidase by the plate method.

\begin{tabular}{||c||c||c|}
\hline $\begin{array}{c}\text { S. pyogenes } \\
\text { isolate }\end{array}$ & $\begin{array}{c}\Delta T^{*} \\
(\mathrm{A600} \mathrm{nm})\end{array}$ & $\begin{array}{c}\text { Hydrolyzed } \\
\text { zone }(\mathrm{mm})\end{array}$ \\
\hline \hline $\mathrm{S16}$ & $\mathbf{0 . 2 7}$ & 12 \\
\hline \hline $\mathrm{S20}$ & $\mathbf{0 . 2 8}$ & 7 \\
\hline $\mathrm{S28}$ & $\mathbf{0 . 2 8}$ & 10 \\
\hline $\mathrm{S30}$ & $\mathbf{0 . 0 7 4}$ & - \\
\hline
\end{tabular}

$\Delta T^{*}$-Reduction in turbidity of broth cultures after 30 min at $37^{\circ} \mathrm{C}$ (A600nm) (Uninoculated culture broth as blank). -Increase in turbidity (A600 $\mathrm{nm})$ after 30 min. at $37^{\circ} \mathrm{C}$. 
$\mathrm{mm}^{*}$ Diameter was calculated after subtracting the diameter of the well $(5 \mathrm{~mm})$.

Hyaluronidase production by Streptococcus pyogenes and other pathogenic streptococci (groups B, C, and G and Streptococcus pneumoniae) has been a subject of interest since early reports of McClean (19), who described an extracellular factor present in the culture supernatants of these organisms capable of cleaving hyaluronic acid. The substrate of hyaluronidase is hyaluronic acid, a sugar polymer composed of alternating $\mathrm{N}$ acetylglucosamine and glucuronic acid residues. Hyaluronic acid is found in the ground substance of human connective tissue and the vitreous of the eye and also is the sole component of the capsule of group A streptococci. The capsule has been shown to be an important virulence factor of this organism by virtue of its ability to resist phagocytosis $(20,21)$

\section{Streptokinase production}

Results showed that all four isolates of $S$. pyogenes were able to produce streptokinase enzyme by creating clear zones around wells containing their cultures in the skim milk agar plate, as shown in Fig. (3).

This result was in accordance with that obtained by Vandammeet al. (17) who reported that most of the streptokinase are obtained from $\beta$-haemolytic streptococci of human and animal origin, and belong to the Lancefield groups $\mathrm{C}, \mathrm{G}$ and also to $S$. pyogenes.

Streptokinase assaying by the radial caseinolytic activity is one of the oldest methods used mainly for the qualitative determination of the enzyme (18). This method depends on direct measurement of the area of the transparent lysis zone in a skim milk agar.

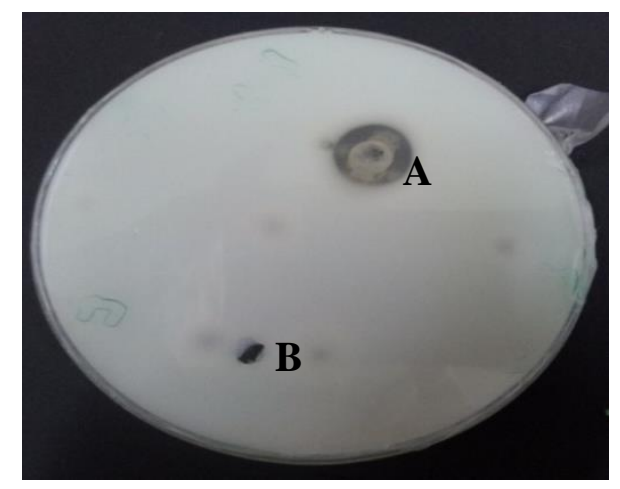

Fig. (3) Biological activity of streptokinase by using Radial Caseinolysis assay.

A) supernatant of $S$. pyogenes isolate 20

\section{broth containing streptokinase, B) control (brain heart broth alone.}

\section{References}

[1] Bisno A L, "Streptococcus pyogenes" p. 1786-1799. In G. L. Mandell R G, Bennett and R Dolin (ed.), Principles and practice of infectious diseases, vol. 2. Churchill Livingstone, New York, N.Y, 1995.

[2] Ebell MH, Smith MA, Barry HC, Ives K, Carey M. "The rational clinical examination: does this patient have strep throat" JAMA;284:2912-8, 2000.

[3] Walker MJ, McArthur JD, McKay F,Ranson M, "Is plasminogen deployed as a Streptococcus pyogenes virulence factor?"; Trends Microbiol; 13: 308-313, 2005.

[4] Nizet V, "Streptococcal beta-hemolysins: genetics and role in disease pathogenesis". Trends Microbiol; 10: 575-580, 2002.

[5] Cole JN, McArthur JD, McKay FC, Sanderson-Smith ML, Cork AJ, Ranson M, Rohde M, Itzek A, Sun H, Ginsburg D, et al. "Trigger for group A streptococcal M1T1 invasive disease"; Faseb J 20: 17451747, 2006.

[6] Parry MA, Zhang XC, Bode I. "Molecular mechanisms of plasminogen activation: bacterial cofactors provide clues". Trends Biochem Sci 25: 53-59. 2000

[7] Hynes WL, Walton S, "Hyaluronidases of Gram-positive bacteria". FEMS Microbiol. Lett. 183, 201^207. 2000.

[8] Abdelghani TT, Kunamneni A, Ellaiah P, "Isolation and mutagenesis of streptokinase producing bacteria"; Am. J. Immunol., 1(4), 125-129, 2005.

[9] Bergey DH, Holt JG, "Bergey's manual of determinative bacteriology"; 9th edn., Lippincott Williams and Wilkins, Philadelphia 2000.

[10] TamYC, Chan ECS, "Modifications enhancing reproducibility and sensitivity in the turbidimetric assay of hyaluronidase"; J Microbiol Methods 1: 255-260, 1983.

[11] Sabuj S, Satyaranjan M, Anindita N, Sashi K P, Prasana K P, Sashi K D, Poluri E, "Isolation, Screening and Characterization of Hyaluronidase Producing Bacteria” 5(2): 95-102, 2009.

[12] Babashmasi M, Razavian MH, Nejadmoghaddam M R, "Production and purification of streptokinase by protected 
affinity chromatography"; Avicenna J. Med. Biotech., 1(1), 47-51, 2009.

[13] Pulicherla KK, Gadupudi GS, Rekha VPB, Seetharam K, Anmol Kumar, Sambasiva Rao KRS. "Isolation, Cloning and Expression of Mature Staphylokinase from Lysogenic Staphylococcus aureus Collected from a Local Wound Sample in a Salt Inducible E.coli Expression Host." International Journal of Advanced Science and Technology 30:35-42, 2011.

[14] Tam Y C, Chan EC, "Modifications enhancing reproducibility and sensitivity in the turbidimetric assay of hyaluronidase"; J. Microbiol. Methods. 1: 255-60, 1983.

[15] Smith R F, Willett N P, "Rapid plate method for screening hyaluronidase and chondroitin sulfatase- producing microorganisms" Appl. Microbiol. Vol. 16. 9 : pp 1434- 1436, U.S.A 1968.

[16] King S. J, Allen A G, Maskell D J, Dowson C. G, Whatmore A M, "Distribution, Genetics diversity and variable expression of gene encoding hyaluronatelyase with the Streptococcus sius"; Pop. J. bacterial. 189(14): 4740-4747, 2004.

[17] Vandamme P, Pot B, Falsen E, Kersters K, Devriese L.A, "Taxonomic study of Lancefield streptococcal groups C, G, and L (Streptococcus dysgalactiae) and proposal of S. dysgalactiae subsp. Equisimilissubspnov"; Int. J. Syst. Bacteriol., 46, 774-781, 1996.

[18] Lei B, Mackie S, Lukomski S, Musser J $\mathrm{M}$, "Identification and immunogenicity of group A Streptococcus culture supernatant proteins". Infect Immun 68, 6807-6818. 2000.

[19] McClean D, "The capsulation of streptococci and its relation to diffusion factor (hyaluronidase)"; J. Pathol. Bacteriol. 53:13-27. 1941.

[20] Stern R,Jedrzejas M J, "Hyaluronidases: their genomics, structures, and mechanisms of action", Chemical Reviews, vol. 106, no. 3, pp. 818-839, 2006.

[21] Starr C. R, Engleberg N C, "Role of hyaluronidase in subcutaneous spread and growth of group A Streptococcus", Infection and Immunity, vol. 74, no. 1, pp. 40-48, 2006.

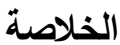

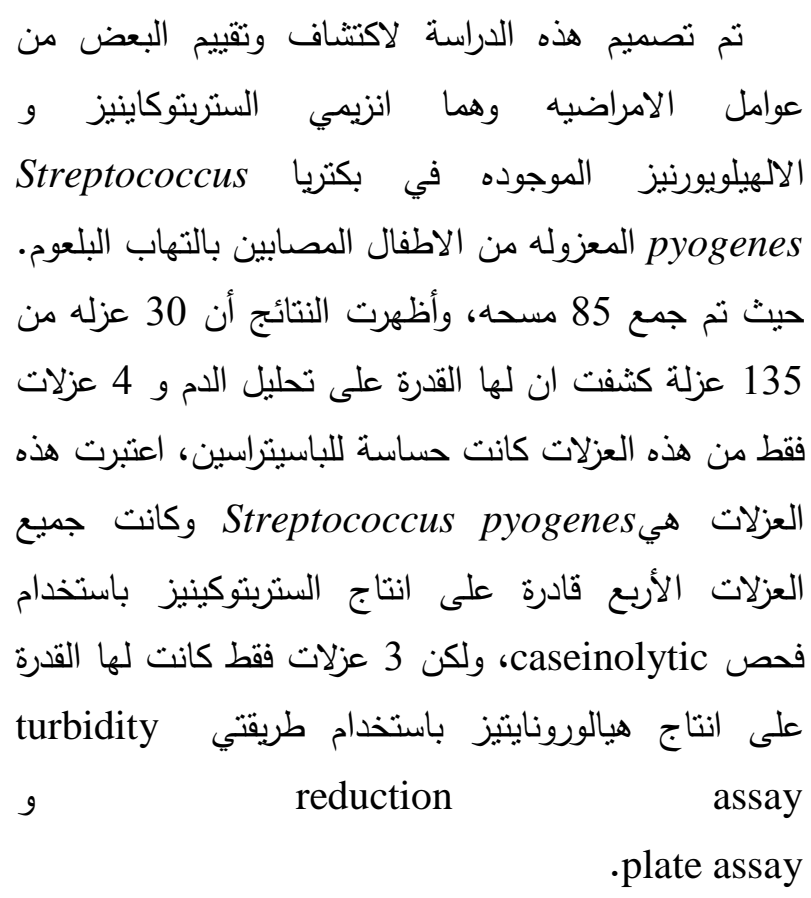

assay 